\title{
Introduction
}

This article explores how an organisation - Jabiru Community, Youth \& Children's Services (Jabiru) - integrates a learning 'community' philosophy and a set of intentional practices into its work with children. This organisation, established in 1993, distinguishes itself from others in that it does not treat community as an item on a checklist linked to audit and compliance regimes. Instead, since inception the organisation has adopted a community development approach (Westoby \& Morris, 2011).

The research, conceptualised in 2018 as a partnership between academics from Queensland University of Technology and Griffith University, and two Jabiru School Aged Care (SAC) services, took place in 2019 through document analysis, observation of services, and focus groups with educators. Our analysis foregrounds the way a philosophy of 'community' is put into practice. We analyse how this philosophy and practice supports children's learning, and discuss how community creates a new kind of 'neighbourhood' at a time when Australian communities are increasingly atomised and fragmented (Cleveland, Newton and Bower, 2018). With this context in mind, we argue - based on findings and analysis - that SAC can constitute a significant 'third space', one alluding to Lefebvre's rights to social space within cities where space is produced primarily by economic drivers (Lefebvre, 1974). SAC temporally sits between family life and schooling. It offers alternative relational possibilities that set it apart from the structure of schooling, and the atomisation of family and community life. Following an overview of the SAC policy-programme-regulatory context and the story of Jabiru, we will examine the relevant literature, locate the study conceptually, and outline the methodology. Our analytical findings are considered before a final discussion and conclusion.

\section{Background and context}

\section{SAC in Australia}


School-age Care programs are a significant site of care, play and education for Australian children (aged five to twelve years) and their families. While after school activity programs have been provided in Australia for over 100 years, these very early programs were recreational (Cartmel, 2007, Hurst 2019). The demand for after school activities began to increase in the 1970s as women's increased participation in the workforce produced demand for custodial care of school-age children (Brennan, 1994; Hurst 2019). Attendances have grown from approximately 85,800 attendances per day in 1993 to 363,700 in 2017 (ABS, 1994; ABS, 2018). Approximately one in three children attend SAC (Baxter, Hand, \& Sweid, 2014).

This growth in Australian SAC mirrors international growth of services. Demand has been shaped by societal changes including family demographics, workforce patterns and changing conditions of socialisation (Schuepbach, 2018). There are an array of different models that have developed independently of each other. Services are managed by a range of community and faith-based organisations as well as privately funded corporate services.

In Australia, SAC has undergone continual transformation in terms of function and how it is conceptualised by community and government. In the 1980s its function was primarily to provide custodial care (Cartmel, 2007). Piscetilli and Mobbs (1986) referred to it in the title of their book as the 'new extended family at school'. The recreational and custodial focus of the 1980s encouraged adultdirected approaches to programming which have since given way to play-based, child-directed practices common to the neighbourhood play of children (Hurst, 2017). In 2009, a suite of legislated reforms which included a curriculum framework 'My Time, Our Place, Framework for SAC in Australia' (MTOP) and a set of standards (Australian Children's Education \& Care Quality Authority (ACECQA), 2019). The framework and standards provide broad guidelines, that are interpreted by educators into practices that are suited to their SAC service and community (Hurst, 2017). 


\section{Jabiru}

Established in 1992, Jabiru, based in metropolitan South East Queensland, is a social-purpose, not-for-profit organisation, which partners with children, young people and families, particularly those experiencing vulnerabilities. Jabiru has a unique community-focused practice framework which underpins the operation of school age care programs. Jabiru holds to a vision of school age care services as communities within themselves, that is as neighbourhood sites of community relationship, recreation, learning and creativity.

\section{Literature review}

SAC remains largely under-researched in Australia (Simoncini \& Lasen, 2012; Cartmel \& Hayes, 2016). Children are spending inclusive of five to six hours a day, a significant portion of their daily lives in SAC (Cartmel \& Hayes, 2016). There are also broader contextual factors at play, spurring the uptake of SAC access and influencing the changing landscape of childhood. These include longer working hours, families with both parents in full-time employment (Cartmel, 2009; Hurst, 2019), single parent families, changing community and interfamilial care-giving dynamics, and the rapid uptake of technology. Internationally, SAC services work with these dynamics and are increasingly becoming a vital conduit between home-life and school-life (Noam, Triggs \& Triggs, 2018; Schuepback, 2018).

Australia is behind its global peers in terms of evidence-based research in this significant sector (Cartmel \& Hayes, 2016). One Australian study emphasised the need for effective inter-stakeholder communication between parents, schools, and national bodies to improve the level of care within SAC services (Cartmel \& Greishaber, 2014).

Another study investigated the different models of SAC providers; comparing the differing circumstances, systems, and structures that affected the ability for services to provide quality care (Simoncini \& Lasen, 2012). An assemblage of factors, such as the quality of relationships with school principals, the 
qualifications and experience of coordinators, encouragement of educator's ongoing learning and development and access to external supports, all surfaced as key determinants in the provision of quality care for children (Simoncini \& Lasen, 2012).

There are a wide variety of stakeholders in SAC (Noam, Triggs \& Triggs, 2018). Horgan, O’Riordan, Martin and O'Sullivan (2018) argue that we have limited understanding of how children experience and value SAC. The Australian research in this area to date indicates that children value play, freedom, and support from non-intrusive adults (Hurst, 2017). As such, this research project seeks to create new knowledge about the burgeoning SAC sector from the perspective of two key stakeholder groups: children and educators.

\section{Conceptual framework}

Our conceptual framework for observing, understanding and analysing the practices of a 'community' is provided by Finnish sociologist Allardt's classical model of wellbeing: having, loving, and being (Allardt, 1976). Despite risks of any normative wellbeing model (e.g. Maslow's) and cognizant of significant critiques (such as Max-Neef, 1992), we determined that Allardt's model constitutes a useful conceptual scaffold for this research as the three dimensions mirrors and aligns with Jabiru's philosophy of community, which emphasises trust, belonging, and the right to navigate space with autonomy. Allardt's framework facilitates an analysis of the dynamic and context-specific generation of learning communities in SAC contexts. Having refers to access to material resources, loving refers to meaningful, respectful interactions with others, and being encapsulates opportunities for autonomous action without alienation. The "having, loving, being" model guided our approach to fieldwork and also informed how we structured our analyses.

The experience of relationship is important for children's sense of who they are and who they can become (Cartmel, 2009). As such, the active negotiation of relationships speaks to both 'loving' and 'being' in Allardt's framework. 'Being' is 
more than physical presence in space - it entails an individual's sense that they belong, are respected, and in this context, are free to initiate activities they value. Finally, 'having' pertains to material resources and conditions, such as access to and use of enriching play equipment; and the provision of generous physical environments in which to move and play. This emphasis on the importance of dynamic practice informed our decision to undertake observations in SAC settings. Observations were specifically focused on children's activities in each service. As the practice is informed by a philosophy of community, we elected to couple these observations with focus groups to understand how educators worked with the Jabiru vision and translated this into intentional practice.

\section{Methodology}

\section{Research questions}

The primary research question guiding this project is: 'What are the practices of children and educators that enable or/and create a learning community in SAC?' A guiding assumption of this research is that the experience of creating SAC as a learning community is informed by the actions and priorities of a range of stakeholders and is also facilitated by educators who exercise a specific set of skills as professionals.

\section{Project design}

This research was conducted at two Jabiru School Age Care community services in Brisbane, South East Queensland. One site services children at an outerNorth school, while the second supports children at an inner-city school. Both centres are well established: each has operated for a decade or longer, though the inner-city service is larger and employs more staff, owing to differences in the school sizes. Each service has an indoor hub on the school grounds that serves as a meeting point and play area for the children. Both services have also negotiated with school management to use outdoor play settings. Access to space is 
acknowledged as an ongoing issue in the inner-city service, as the school is at full capacity and demand has outpaced the original design of the school, originally constructed at the turn of the $20^{\text {th }}$ century.

Each centre is nested within different cultural and socioeconomic milieus: the inner-city centre has a higher rate of occupants in fulltime employment, working as professionals, where median weekly earnings for residents aged 15 and over are considerably higher than in the outer-north suburb. In contrast, there is a significantly greater proportion of the outer-north suburb adult population working in trades worker occupations, or clerical and administrative populations. Australian census results also indicate that residents of the outer-north suburb have a higher proportion of one parent families than residents of the inner-city suburb. The cultural compositions of both suburbs are diverse.

We designed a qualitative approach to data collection. We anchored our project in an interpretivist and constructivist methodological tradition, which grants primacy to both experience-near perspectives and sense-making processes of participants.

Key methodological principles have informed the research design and selection of methods. One epistemological assumption is that individuals create meaning and the construction of meaning is a social process (Crotty, 1998). It is therefore important to invite participants to reflect on their activities as it is not possible to 'unearth' an inherent, objective rationale for SAC activities.

Second, embodied experiences (e.g., children's play in SAC centres) are contextspecific: it is therefore important to attend to the situatedness of experience (Merleau-Ponty 2013).

Our approach to data collection for each participant group is detailed below. We offer a rationale for each approach in light of our project aims, and methodological principles.

\section{School-age Care Educators}

We elected to engage educators in focus group discussions regarding their role in relation to creating and curating learning communities in SAC settings. SAC 
educators work in collaboration, and Jabiru educators regularly participate in supervision and practice reflections. In light of this, we opted for a collaborative data collection exercise in preference to a one-on-one interview. It was important that we explored educators' accounts of their practices, what they aspired to achieve, and how they believed SAC is regarded by School Principals and the wider community.

Furthermore, focus groups are regarded as an effective method for offering participants the opportunity to engage in group discussion in an encouraging, non-threatening environment. Focus groups are also considered preferable to one-on-one interviews in this context as they encourage dynamic reflection and discussion. This is for gaining an understanding of educator experiences of cocreating learning communities, and for exploring what factors enable and/or constrain their efforts.

\section{Children enrolled in SAC}

Epistemologically, our positioning of community and practice guided our decision to undertake observations of children's activities. We hold that 'community' is not a stable, objective reality 'out there', but a fluid, multifaceted phenomenon that is created through practices. Observing practice is important for gaining insight into how community is created. Furthermore, practices that inform the creation of learning communities may also involve actions and behaviours that are not obvious to the individual/s executing them- some actions or activities may be normative, or carried out with little prior planning (such as when children are being spontaneous or responding to unforeseen events), as such they may be difficult for children to discuss in settings such as focus groups. Understanding the creation of learning communities therefore entails an investigation of children's activities and interactions in physical context (e.g. their use of play equipment) (Ritchie et al, 2013 p.245). We acknowledge that given our stated focus on sense-making rationales, facilitating group discussions with children about their views on SAC would have been a fruitful addition in the research design for this project. Owing to time and resource constraints, we contained the methodology to focus groups with educators and observations of children's 
activities. We prioritised observations with children over focus groups or interviews, owing to our interest in the dynamism of practice, and how participants of SAC actively co-create community.

\section{Data collection}

Initially, the researcher responsible for data collection made an informal visit to each service of an afternoon, prior to students arriving, to meet the service's staff and answer any questions about the pending research activities. While the research design involved the input of service managers over a number of months, this meeting also served as an opportunity to 'break the ice' with centre staff.

Initially, one observation was undertaken at each service before focus groups were held. Each observation ran from $2.30 \mathrm{pm}$ to $5.30 \mathrm{pm}$ on a mid-week afternoon (shortly before children ended formal schooling for the day, to shortly before closing time). Approximately 30 children were observed in the outer north service, while approximately 65 children were observed in the inner-city service.

Observations were undertaken before the focus groups so that the researcher could gain a sense of the dynamism of practice in each centre before engaging the staff in discussions about their practice. The researcher also wished to avoid being biased by staff accounts of their practice while they undertook the observations.

Observations were held in mid-May 2019. In the lead up, posters were placed in each service advising parents of the research project, and information sheets and consent forms were sent home with parents and children. Age-appropriate consent forms were designed for children aged 5 to 7, and children aged 8 to 12 (with the language adjusted for each cohort). Children and parents were informed that children would have the option of wearing different coloured wrist bands on the day: warm coloured wrist bands for children who wished to be involved, cool coloured wrist bands for children who did not wish to be involved. Consent was required of both parents and children, and children could opt out on the day. The researcher avoided observing the activities of individual children 
wearing 'opt out' wrist bands. In practice however, children who opted out of the research were few in number $(n<5)$ in each service.

For the observation we used a custom-designed observation recording tool. The tool consists of two proformas: one designed to encourage close attention to detail, a second designed to encourage reflection on the overall culture and setting.

Generally, the detailed proformas would be completed before the researcher would detail their broader impressions in the second, 'Stepping Back' proforma.

Focus groups were held in late May and early June with the full composite of staff at each service. Seven staff participated in the outer north service, while five staff participated from the inner-city service.

Focus groups with educators were semi-structured. Sessions were guided by a schedule that addressed educators' views on:

- What sets Jabiru apart: Jabiru's philosophy and what they believed the service is trying to achieve?

- How the organisational vision translates to on-the-ground practice?

- What values/principles educators bring to their work?

- What they believe children gain from attending Jabiru; e.g. what do children learn at Jabiru that they may not learn at home or at school?

- What spaces the service can access: which are enabling, and which are constraining for children's activities?

\section{Data analysis}

Initially, the researcher responsible for data collection wrote seven memos based on analysing and reflecting on the observation proformas. These memo's used stories observed and reflection, structured through the conceptual framework of 'having, loving and being' to foreground key community-oriented practice. Then, the two lead researchers fully immersing themselves in the memo's and focus group transcripts highlighting key themes. Themes were identified manually using a white board and post-notes. Key stories illustrative of practices were discussed, and analytical themes were identified. 


\section{Ethics}

Ethics for this research project was approved by Queensland University of Technology, under full-review, in April 2019.

\section{Finding: What makes a [learning] community?}

While an effective SAC space requires appropriate resources, structures and systems, what was significant from our inquiry is the importance of building an intentional culture of community. This is confidently foregrounded in the findings not only because educators talked about it early in focus groups, but because Jabiru has made a 'community philosophy' central to its work since its inception 20 plus years ago (Westoby \& Morris, 2011). As one of the educators suggests, 'Jabiru has more of a community focus [compared to other organizations in the SAC space].' This educator also explained that while a 'community philosophy' is encouraged as industry standards, at Jabiru 'community actually underpins our philosophy', the model of community is in our DNA'.

Focus group discussions revealed how community is deployed as a philosophy and set of practices at Jabiru for the purposes of learning. This aligns with a shift addressed in the literature review: while SAC originally emerged as a custodial solution for working parents and was initially positioned as a recreational holding space for children; there has been a shift in the provision of care to be enriching and generative for children.

In analyzing the data our findings focus on how the learning community is mainly fostered as a learning experience through emergent play. This involves focusing on spatial, social and emotional dynamics (understood through the tripartite wellbeing model of 'having, being, loving').

Within our analysis, this kind of learning community can also be understood as a third space, named as the 'new neighbourhood'. For example, in one of the focus 
groups with SAC educators, the manager of one service shared a story about the children that attend their centre:

When I was a child, I would play with my friends until the sun went down outside - whereas these kids, they'll be super excited if they run into a friend of theirs in the elevator. And that's their neighbourhood chat, it might be a 30 second chat before you get off at the second floor and your friends get out and then you go up. But then you get here, and they'll say "oh, Johnny lives with me".

In a sense this story illustrates the lack of unstructured sociality and play in the contemporary neighbourhood, and foregrounds how such play and sociality is significant within the new spatial and social dynamics of modern urban life. Intentional community practice at the SAC service then is crucial as a third space 'between' the structured life of school hours and atomized community life.

\section{Belonging, trust and promises}

At the heart of the Jabiru philosophy and practice of community is the creation of a genuine sense of belonging for children. Belonging was mentioned several times by educators and observed in the activities of children (discussed in greater detail below). According to the Jabiru educators, the glue to belonging was trust, which they explained is cultivated through honouring several key 'promises'. Contextual reading clarified that while Jabiru as a whole organization develops what they call a Community Code, the two services who participated in this research indicated that children have identified with the word 'promises' as an easily relatable and memorable language to frame the four key commitments of the Community Code.

These include:

- I promise to stay in the right place at the right time.

- I promise to treat other people and everyone each with respect.

- I promise to take responsibility for my actions.

- I promise to help other people when they need it. 
Educators explicitly talked about building trust, and what is meant can be understood by the following narrative:

We say [to children], 'we trust you', and don't worry about asking us permission. Just do it, but know that if you're going to do it, you've got to be following through the promises.

Importantly these 'promises' are considered key to creating a culture of community that avoids ' 10 million rules' (a statement used by one of the educators). The emphasis on belonging and trust draws attention to the importance of relationships (underscored by the explicit value placed on respectful interaction and help-offering) and it also draws attention to the right to exercise autonomy ('we trust you, and don't worry about asking us permission') responsibly ('I promise to take responsibility for my actions') without alienation (exemplified by the desire to avoid imposing '10 million rules' to regulate children's conduct). In this way, educators' spoken interest in encouraging belonging marries the loving and being dimensions of Allardt's framework. This is also a doorway to a learning process for children. Children have to take the code and apply it to the context to work out how to self-regulate their behaviour and choices. As such, it gives them an opportunity to experiment, experience different responses, reflect and change.

Later in one of the focus groups, educators returned to this theme of trust. They explained that they communicate to the children:

We have your backs. If you do this, I trust you. I'm going to have your back. That's why we've built a strong team. The trust and relationships.

This overt commitment to 'having your back' is also important for educators' relationship with children. It underscores a kind of mutuality. The context for this was explained by an educator, as follows:

They might really injure themselves badly, whatever. It's like, "Here in this moment, you understand that I am doing everything I can to help you. Regardless of what's happened before." It's really reassuring because they know ... If you say you're going to do something, you've made a 
commitment. If a kid makes a commitment to us, 'next time I will put my bag in the right place', whatever you expect them to keep it. But if we make a commitment, we've got to keep our end of the deal as well.

This commitment to encouraging a secure sense of belonging for children is arguably important for their learning. Children are shown that they can act responsibly, and they are granted social/relational space to pursue activities with a degree of autonomy because they are told, or/and have displayed that they are trustworthy. This also means that children can make mistakes or have misadventures without dire social consequences: what the above extract speaks to is educators' unwavering commitment to supporting children, including when things go wrong. The expectation for commitment on both sides can arguably support children to learn what is involved in cultivating and sustaining a mutual, responsible relationship.

\section{The invisible work of nurturing a culture}

The analysis of educators is that these practices create a culture of community, and they understand this as doing 'the invisible work' in the sense that culture is often invisible or intangible, yet it is what makes the Jabiru philosophy possible. There was a sense that this culture, once 'embedded and embodied', which takes some years, 'holds' the work.

This interest in cultivating a sense of belonging that is underscored by promises yet not encumbered by ' 10 million rules' was arguably evident in the observations of the two SAC services. For instance, at the commencement of the observation period at the inner-city service, the first observed activity involved the sharing of afternoon tea. This occurs immediately after school officially finishes for the day. Here is a vignette:

In this activity, the cohort of 35 students were sitting on brightly coloured mats on the school oval, chatting, and eating. Approximately five educators were standing in front of the mats, leaning down to casually chat and play with the children. A female educator is serving food from a small table at the back of the seating area, but the children also wander up and serve themselves. While the activity feels routine, it does not feel overly structured. 
Children eat at their own pace, serve themselves when they are ready, and there is a noticeable absence of directives: at no point are the children instructed on how or what to eat - the caveat being that everyone is behaving in a way that endorses the values of The Community Code. Instead, the conversation with educators seems more 'eye-level' (involving discussion of interests and hobbies: for example, a male educator, in conversation with a child, explained, "I went to the museum on the weekend. I think you'd like it there."). There were no discernible 'in' groups or 'out' groups: children mingled across different age groups (gauging by height and uniform differences), and across different cultural groups. After ten minutes of chatter, the children start to visibly fidget-on sensing this restlessness, the lead educator announces that they are free to go and play. All up, this afternoon tea felt festive: children seemed energized and the overall atmosphere and relationship with educators felt relaxed. The lack of rigidity exemplifies educators' interest in refraining from imposing '10 million rules'. In line with the four promises, the children are in the right place at the right time', yet are otherwise free to relax.

Overall, this observation conveyed that SAC belongs to the children. The lacking evidence of cliques or ostracized children also offers some evidence that this is a site where relationships are not overly strained, where children may comfortably exercise a right to autonomy while holding respectful relationships with their peers and educators. The observation also suggests a reasonably confident usage of space (e.g. children serve themselves food), and these spatial dynamics (of 'having' in Allardt's model) will be further explored below.

\section{A conversational practice}

Importantly, when workers educators were asked about whether they talk about the four promises explicitly, the focus group discussion foregrounded that the practice is not so much about repeating the promises as abstract principles to be followed, but as a basis for real conversations, between educators and between educators and children. 
Educators emphasized this conversational practice as building trust, and as modelling a way of being that encourages responsibility for self and responsibility toward others. In the focus groups educators spoke about families being highly stressed and that household conversations were not the 'norm'. For instance, at the inner-city service, the lead educator explained,

...over the last few days we've spent probably a total of two or three hours talking about interventions for a particular child who's got some transition issues happening at home and it's crazily impacting his behaviour, and his emotional levels, and how he's identified that he wants to see a psychologist now. And we're being the conduit for him because he can't speak to his parents or his teacher about it.... And we have the skillset to deal with that.

The educator explained that as a result of the trusting relationship educators cultivate with children and the sense of belonging they have to SAC, children are capable of initiating vulnerable conversations and taking responsibility for sometimes volatile behaviours. The example of a child who had previously exhibited physical aggression now being able to approach the educator to explain, "I think I want to tell my dad that I don't like his girlfriend.... "Can you help me tell my teacher tomorrow that I don't like my dad's girlfriend?"

While injunctions to 'be responsible' might not be repeated ad nauseum, it nonetheless carries through the practice of Jabiru educators and it in turn shapes the conduct of children. Educators' commitment to unconditional positive regard for children, and in turn children's willingness to ask for help for life challenges speak to the loving dimension of Allardt's model: educators and children are actively working hard to cultivate honest relationships characterized by mutual accountability. The way educators actively speak to valuing children and cultivating interventions to support them encourages learning and maturation. In the context of the inner-city service, it appears that children ask for help with significant challenges in an environment where educators repeatedly demonstrate trustworthiness. The work of collaborating to design an intervention for a child who is struggling speaks to the importance placed on a child's right to belong. The language used by the educator in the above excerpt 
also appears careful and considered, and according to educators is an intentional practice. At no point is the child positioned as 'the problem'. Instead, a child is impacted by transitions, and this has implications for how he conducts himself. This is respectful and professional phrasing. Here, there is a demonstrated active interest in meeting basic needs for being and loving, and in turn this creates space for children to learn how to express their needs and ask for help in meeting them.

\section{Relationship underscored by empathy and authenticity}

With trust and inclusion as the glue to a culture of community, and conversational practice as crucial, relationship becomes central. A real conversation cannot occur outside of a genuine relationship in which the young person trusts the educator. This was explicit in the focus groups, whereby educators explained how,

You can't be fake 30 hours a week to people. It's almost like a home environment. You're eating breakfast with them. You're here at six o'clock at night when there's you and one other kid. They're waiting for their parents and they've been here for 12 hours. You can't be fake with them. You've got to be you. You might have to temper some elements of you. You're still you. You're not wearing a mask.

This sense of authenticity appears to support feelings of solidarity among the children, trusting that the educator is accompanying them. One worker explicitly stated that, 'The children feel the stability amongst us and the solidarity'. This kind of comment and invisible work sums up Allardt's sense of loving.

The commitment to authenticity and 'being real' also appears to translate into children's relationships with one another. During observational sessions at both services children were engaging in conflict, conflict resolution, and negotiation in different contexts. Children exercised a degree of autonomy over their actions and interactions (as discussed above), so they had the space to work through conflicts without educators intervening to control or discipline the proceedings. 
For instance, during an observation of an indoor play session at the inner-city service, the researcher observed how children actively moved between collaboration and conflict. Here is a second vignette:

Two boys playing a card game would occasionally yank an instruction booklet from one another's hands, talk sharply, and rearrange each other's game pieces- yet continue working together. Educators were present and appeared aware but did not step in to reprimand either child. Similarly, two (and occasionally, three) boys playing with blocks in the far corner of the room had disagreements over block placement- but nonetheless continued playing energetically.

Here children are 'being real' with one another in a similar way to which the educator discussed above. Authenticity will involve being tired, short, and/or frustrated. In a context where this is respected, children have space to negotiate relationships with honesty and learn how to self-regulate anger and conflict (and access support as required or requested). This aligns with Allardt's conceptualization of 'loving'.

The one instance where an educator did intervene was upon request. During an observation of play on an outdoor oval, a group of boys moved in to interact with a group of girls sitting quietly against a building. A boy threw a football against the wall to gain the girls' attention. When one of the girls caught it and threw it against his legs, he retaliated by chasing and kicking her. As she ran past an educator, she called out, "can you distract Anthony?!” and the educator called out, "hey Anthony can you go and collect <inaudible> from inside?" The intervention was subtle and skillful; it served to redirect activity rather than shut down a conflictual moment/event.

\section{Responsibility, risk and freedom}

Another key element of the work of building a culture of community includes thinking about responsibility, risk and freedom. For example, the focus groups illuminate how 'nothing we did is at all risky, but we just give them the freedom to engage in whatever they want' (p11/12). Freedom to participate, engage with 
materials creatively and experiment was evidenced in different ways at both services. For instance, at the inner-city service in the indoor play area, children were observed moving through the space and confidently selecting materials from shelves (e.g. craft supplies) that they wished to work with. Adults did not act as gatekeepers between children and resources, as children were not required to ask permission. Building on this, there also did not appear to be strict directives about what children should do with the materials at hand. During an observation of play on an outdoor oval at in the inner-city site, a group of children were observed playing with hula hoops. Not one child was using a hoop in its traditional sense: instead they threw them, spun them in the air, and smacked them into the ground. Experimenting with the physical limits of materials was not positioned as 'wrong', instead it appeared to be encouraged.

Reflecting further on this theme of responsibility, risk and freedom, educators were clear that they wanted young people to 'make their own choices'. And in comparing the Jabiru children with children from other SAC providers they suggested that 'our kids handle adversity a lot better. They get back up. They handle injuries better...they have more resiliency about them'.

\section{Discussion}

\section{The importance of the practitioner}

We contend that it is the quality of the practitioner (with particular skills sets) that is crucial to fostering a learning community in which children develop skills in negotiating relationships (including conflict), learning to express their needs, making choices and being accountable for their choices. Importantly, the analysis of focus groups suggests that the educator is engaged in what we think of as reimagining schooling processes on two levels. First, in terms of their own career biography in which most educators experience working at Jabiru as a significant paradigm shift to their work in other SAC providers. Second, the educator learns at Jabiru that they must also encourage children to go through their own reimagining process as the children move into what we understand as a generative and educational third space that sits between the contractual 
arrangement of the school, and the dynamics (often limited in terms of time, space, and relational opportunities) of the home/social sphere.

The educator is necessarily reflexive, present, and authentic. There is no formula, and the process of connecting to a philosophy and service vision that foregrounds community is difficult and partial. The key skills are rooted in responsiveness. Any tight planning ahead becomes too rigid and lose their creative agency. Educators must be capable of restraint (not being overly directive) while also still 'showing up' in a way that is responsive to children's invitations. As suggested by the comment about the need to be 'real' with children, the educator must have a willingness to be in the mess - as responsive and adaptive practice is inherently messy, even if skilled. What both the observational and focus group data illustrates is that what matters is the quality of the educator, not just the practice.

\section{Attending to culture - forming community}

Crucial in the findings and analysis is the significance of attending to what we have alluded to as the often invisible, yet formative element of 'community' culture. Recognizing that culture is formed through many daily routinized practices - for example, use of particular language, attending to relationships and trust-building, intervening in possible conflict in skillful ways - the research helped surface the culture in a way that it can be valued and nurtured more intentionally. The research also suggests that it takes time to create such a culture - both in terms of how Jabiru inducts educators into what is obvious (e.g. quality standards) and also how those educators learn the more subtle art of the work (e.g. the use of language/gestures in everyday practice). As such, also contrasting the 'culture' of the SAC space to that of normal school hours (9am$3 \mathrm{pm}$ ) and homelife for many children, helped educators and Jabiru as a whole value their professional work more clearly.

\section{Conclusion: A third space - the new neighbourhood}

Part of the rationale for Jabiru's philosophy of 'community' is not only a deep commitment to a practice - one of belonging, trust, relationship and so forth - 
but one that supports children who spend a significant percentage of their lives on school sites, and not in neighbourhoods, to discover a generative learning community. With their particular response to the wellbeing needs of having, loving and being, our analysis foregrounds the possible role of SAC initiatives as a seemingly vital 'third space' between the ever-increasingly structured worlds of schools and the atomising, fragmented world of modern urban neighbourhoods. With schools increasingly shaped and governed by metrics/audit culture, structures, behavioural and risk management frameworks; and urban neighbourhoods atomising under the forces of neoliberal over-work (the work-life challenge) and precarious labour, SAC spaces fulfil an important third space function. One of our suggestions is that other SAC providers learn this lesson from Jabiru's focus on 'community' and consider how they can create such spaces.

Our findings and analysis also illuminated how children and educators co-create a learning community, and how this learning community heavily relies on playbased, child-directed, quasi-autonomous activities that were a feature of neighbourhood play. As such, SAC as a third-space learning community is a quasi-neighbourhood. The learning community respects and meets children's needs for 'having', 'loving', 'being', that is key to its success and popularity with children. Referred to as the New Neighbourhood, our findings suggest particular characteristics. These include: less structure (as opposed to no structure, or school-like structure), a messy-organic playful space, the importance of what we have called 'the invisible', that is, the culture that shapes and enables a learning community; intentionality of educators; and a playful socially-embodied practice.

\section{References}

Australian Bureau of Statistics (ABS) 1994. Child care Australia, June 1993. Cat. No. 4402.0. Canberra: ABS.

Allardt E (1976) An updated indicator system: Having, loving, being. Helsinki: University of Helsinki Press. 
Australian Children's Education \& Care Quality Authority (ACECQA), 2019 My Time

Our Place, Framework for School Age Care in Australia,

https://www.acecqa.gov.au/sites/default/files/2018-

05/my time our place framework for school age care in australia 0.pdf

Baxter, J. Hand, K., \& Sweid, R. (2014). Families' use of and needs for school aged care, paper presented at Early Childhood Australia National Conference 2014, Melbourne, 4-6 September 2014.

Brennan, D. (1994) The politics of Australian child care: from philanthropy to feminism. Cambridge ; Melbourne ; New York : Cambridge University Press

Cartmel, J. (2007) Outside school hours care and schools. PhD thesis, Queensland University of Technology.

Cartmel J. (2009) Outside School Hours Care and Schools. Educating Young Children: Learning and Teaching in the Early Childhood Years 15(2): 25-27.

Cartmel, J. (2009). Building relationships in outside school hours care. Children in Scotland, 95: 7-9

Cartmel J, and Grieshaber S. (2014) Communicating for Quality in School Age Care Services. Australasian Journal of Early Childhood 39(3): 23-28.

Cartmel J and Hayes A (2016) Before and After School: Literature Review about Australian School Age Child Care. Children Australia 41(3): 201-207.

https://doi.org/10.1017/cha.2016.17

Cleveland B, Newton C and Bower I (2018) The Next Generation of Australian schools, Design, Melbourne, Australia: Learning Environments Applied Research Network. https://pursuit.unimelb.edu.au/articles/the-next-generation-of-australian-schools

Crotty M (1998) The foundations of social research: Meaning and perspective in the research process. St Leonards: Allen and Unwin.

Australian Government Department of Education and Training, 2017 Annual Report 2016-17: Opportunity through learning. Australian Capital Territory: Australian Government. 
Garner R, Yong Z and Gillingham M. (2002) Hanging Out: Community Based after School Programs for Children. Greenwood Publishing Group, Incorporated. ProQuest Ebook Central, https://ebookcentral.proquest.com/lib/qut/detail.action?docID=3000838.

Gilchrist A (2005) The well-connected community: A networking approach to community development. Bristol: Policy Press.

Horgan D, O'Riordan J, Martin S, and O'Sullivan, J. (2018) Children's views on schoolage care: Child's play or childcare? Children and Youth Services Review, 91. Retrieved from http://search.proquest.com/docview/2122756639/

Hurst B (2017) "Eat, play, go, repeat": Researching with older primary-age children to retheorise School Age Care. Doctor of Philosophy Electronic document. University of Melbourne, Vic.

Hurst B (2019) Play and leisure in Australian School Age Care: Reconceptualizing children's waiting as a site of play and labour. Childhood 26 (4): 462-475

Lefebvre, 1974

Mahoney J, Lord H, \& Carryl E (2005) An Ecological Analysis of After-School Program Participation and the Development of Academic Performance and Motivational Attributes for Disadvantaged Children. Child Development 76(4): 811-825. Available: https://doi.org/10.1111/j.1467-8624.2005.00879.x

Max-Neef, M. (1991) Human Scale Development: Conception, Application and Further Reflections, New York \& London: The Apex Press.

Merleau-Ponty M (2013) Phenomenology of Perception. London; New York: Routledge.

Noam, G. G., Triggs, H., \& Triggs, B. B. (2018) Expanded learning: A thought piece about terminology, typology, and transformation. International Journal for Research on Extended Education, 6(2), 165+.

Piscitelli B and Mobbs, J (1986) The new extended family at school: A report of after school care education and playgroup programs in South Australian and Queensland schools. Kelvin Grove, Queensland: School of Early Childhood Studies, Brisbane College of Advanced Education. 
Ritchie J, Lewis J, McNaughton Nicholls C, and Ormston R. (2013) Qualitative research practice: A guide for social science students and researchers. London: SAGE.

Schuepbach, M. (2018) Useful terms in English for the field of extended education and a characterization of the field from a Swiss perspective. International Journal of Extended Education 6(2): 132+

Simoncini K and Lasen M (2012) Support for quality delivery of outside school hours care: A case study. Australasian Journal of Early Childhood 37(2): 82-94.

Wong M (2008) Secrets of Successful Afterschool Programs. Harvard Graduate School of Education. Retrieved from Harvard Graduate School of Education website:

https://www.gse.harvard.edu/news/uk/08/02/secrets-successful-afterschool-programs

Westoby, P and Morris, K (2011) 'Community as dialogue' and 'dialogical community development' with(in) schools, in eds. Bottrell and Goodwin Schools, Communities and Social Inclusion. Australia: Palgrave MacMillian. 